\section{BMJ Open Respiratory Research}

\title{
Adherence to early pulmonary rehabilitation after COPD exacerbation and risk of hospital readmission: a secondary analysis of the COPD-EXA- REHAB study
}

\author{
Jakob Kjærgaard (D , , Carsten Bogh Juhl, ${ }^{2,3}$ Peter Lange, ${ }^{4}$ Torgny Wilcke ${ }^{1}$
}

\begin{abstract}
To cite: Kjærgaard J, Juhl CB, Lange $\mathrm{P}$, et al. Adherence to early pulmonary rehabilitation after COPD exacerbation and risk of hospital readmission: a secondary analysis of the COPD-EXA-REHAB study. BMJ Open Resp Res 2020;7:e000582. doi:10.1136/ bmjresp-2020-000582
\end{abstract}

Received 26 February 2020 Revised 24 July 2020 Accepted 24 July 2020
D) Check for updates

(C) Author(s) (or their employer(s)) 2020. Re-use permitted under CC BY-NC. No commercial re-use. See rights and permissions. Published by BMJ.

For numbered affiliations see end of article.

Correspondence to Dr Jakob Kjærgaard; jakob@naj.dk

\section{ABSTRACT}

Background Early pulmonary rehabilitation after exacerbation of chronic obstructive pulmonary disease (COPD) has previously been shown to reduce the risk of hospital admission and improve physical performance and quality of life. However, the impact of attendance at early rehabilitation programmes has not been established.

Objectives To evaluate the impact of increasing attendance to pulmonary rehabilitation on the risk of hospital admission, physical performance and quality of life in patients attending an early rehabilitation programme after an exacerbation of COPD.

Methods This study was a secondary exploratory analysis of the randomised controlled trial COPD-EXA-REHAB study, involving patients hospitalised with an exacerbation of COPD. The COPD-EXA-REHAB study compared early pulmonary rehabilitation, starting within 2 weeks after an exacerbation, with standard treatment, that is, the same programme starting 2 months later. The present analysis included only the 70 patients allocated to early pulmonary rehabilitation. Results At 1-year follow-up, we found an association between the number of sessions attended and a reduction in hospital admissions (incidence rate ratio $0.93(95 \% \mathrm{Cl} 0.88$ to 0.99 ), $p=0.02$ ), corresponding to a $7 \%$ reduction for each session attended. Similarly, at 2-month follow-up, physical performance was positively associated with sessions attended: the mean Incremental Shuttle Walk Test result improved by $8 \mathrm{~m}$ with each session $(95 \% \mathrm{Cl} 2.54$ to 13.56 , $\mathrm{p}=0.005)$ and the Endurance Shuttle Walk Test result by 44 $\mathrm{s}(95 \% \mathrm{Cl} 18.41$ to $68.95, \mathrm{p}=0.001)$. Quality of life, assessed using the COPD Assessment Test, was not significantly associated with the number of attended sessions, with the average score increasing by 0.15 points with each session $(95 \% \mathrm{Cl}-0.35$ to $0.65, \mathrm{p}=0.55)$.

Conclusion Increased attendance at early pulmonary rehabilitation after exacerbation of COPD was associated with reduced risk of hospital admission and improved physical performance.

\section{BACKGROUND}

Pulmonary rehabilitation in patients with chronic obstructive pulmonary disease (COPD) is a comprehensive intervention comprising supervised exercise and

\section{Key messages}

What is the key question?

- How does attendance impact the effect of early pulmonary rehabilitation after exacerbation of chronic obstructive pulmonary disease (COPD)?

What is the bottom line?

- Increasing attendance is associated with improved benefit of early pulmonary rehabilitation.

\section{Why read on?}

- This post hoc analysis provides evidence that increased attendance at early pulmonary rehabilitation after exacerbation of COPD is associated with reduced risk of hospital admission and improved physical performance.

education, which increases physical performance, reduces symptoms and improves quality of life. ${ }^{1} 2$ In addition, increasing evidence suggests that early pulmonary rehabilitation following acute exacerbation of COPD has a beneficial effect on hospital admission and mortality. ${ }^{3} 4$ As a result of the evidence for these positive effects, early pulmonary rehabilitation is highly recommended in most guidelines for the management of patients with COPD. ${ }^{56}$

However, adherence to the rehabilitation programme in stable COPD is low. ${ }^{7} \mathrm{Up}$ to $50 \%$ of the patients referred to rehabilitation never attend a single session. ${ }^{9}$ Factors that influence non-participation in pulmonary rehabilitation may be environmental, such as long travel distance and transport issues, social factors such as lack of support from family and friends, or lack of perceived benefit from rehabilitation. ${ }^{111}$ Other factors associated with poorer adherence to rehabilitation include current smoking, low quality of life, anxiety and depression. ${ }^{12}$ Although 
the potential benefits of early pulmonary rehabilitation following an exacerbation are greater than in stable COPD, similar problems exist regarding adherence. A UK audit on early pulmonary rehabilitation reported that only $48 \%$ of the referred patients completed the rehabilitation programme, and similar results have been found in other trials. ${ }^{13} 14$ It is assumed that poor attendance may have a negative influence on the effect of early pulmonary rehabilitation in COPD, but this needs to be confirmed.

In our previous randomised controlled trial (RCT) study, COPD-EXA-REHAB, we compared the efficacy of early REHABilitation starting within 2 weeks following an EXAcerbation versus late pulmonary rehabilitation that started 2 months after an exacerbation of COPD. Although adherence in the early rehabilitation group was significantly higher than in the late rehabilitation group, it was still only $56 \%$. $^{15}$

In the present exploratory study, we therefore analysed the impact of attendance at an early rehabilitation programme shortly after a hospitalisation for an exacerbation on hospital readmission, physical performance and quality of life.

\section{METHODS}

\section{Study design}

This study was a subgroup analysis of the COPD-EXAREHAB study, which was an investigator-initiated, randomised, single-centre, open-label clinical trial in patients hospitalised with an exacerbation of COPD. The patients were randomised either to early pulmonary rehabilitation within 2 weeks of discharge or to standard rehabilitation after 2 months in the stable phase. The ClinicalTrials.gov registry identifier was NCT02987439.

\section{Study population}

Eligible patients admitted with an acute exacerbation of COPD to the Department of Respiratory Medicine, Gentofte Hospital, from 2013 to 2016 were included. The inclusion criteria were hospital admission with acute exacerbation of COPD, a diagnosis of COPD, age $>18$ years and capability to walk $10 \mathrm{~m}$ independently. Exclusion criteria were the inability to provide written consent and understand Danish, estimated life expectancy of under 6 months due to other serious illnesses such as heart disease or cancer, participation in another rehabilitation programme, living in a nursing home and residence outside Gentofte Hospital's recruitment area. The present analysis only included the patients in the early rehabilitation group.

\section{Pulmonary rehabilitation programme}

The pulmonary rehabilitation programme was a 7-week outpatient programme composed of twice-weekly oneand-a-half-hour supervised training sessions and weekly $1 \mathrm{~h}$ multidisciplinary educational sessions, in accordance with the Danish Health Authority's pulmonary rehabilitation guideline for patients with COPD. ${ }^{16}$ The training sessions were supervised by a physiotherapist and consisted of endurance and resistance training at moderate to high intensity (Borg scale of perceived exertion (CR10) 4 to 7). The educational programme aimed to improve the patients' management of their disease, maintenance of physical activity and exercise training at home, smoking cessation, use of medication, coping strategies, diet and handling of exacerbations.

\section{Primary outcome}

Risk of hospital admission within the 12-month study period.

\section{Secondary outcomes}

Increase in exercise performance, measured by the incremental shuttle walk test (ISWT) and endurance shuttle walk test (ESWT), and health-related quality of life, measured by the COPD Assessment Test (CAT) at 2 months after inclusion, at the end of the rehabilitation programme. The ISWT is a test to measure maximal exercise performance. The ESWT measures submaximal exercise performance corresponding to $85 \%$ of $\mathrm{VO}_{2} \max$ calculated from the ISWT.

\section{Statistical analysis}

Baseline characteristics are presented as mean (and SDs) for parametric data and median (and IQR) for non-parametric data. Categorical data are presented as frequency and percentage. After checking for collinearity $(\mathrm{r}<0.70)$, we used backwards stepwise elimination for all baseline characteristics to retain variables in the multivariate models for the different outcomes $(p<0.10)$. The primary outcome was analysed with negative binomial regression, and sensitivity analysis using logistic regression was performed on the impact of adherence on hospital admissions. Adherence was defined as attending $>75 \%$ of rehabilitation sessions, as in the original study paper. ${ }^{15}$ For the secondary outcomes, we used a general linear regression for the ISWT, ESWT and CAT. Statistical significance was set at an alpha level of 0.05 . The statistical analyses were performed using Stata V.13 (Stata Corporation, College Station, TX, USA).

\section{RESULTS}

\section{Baseline}

A total of 70 patients were allocated to early pulmonary rehabilitation. At inclusion, the patients were an average 72.7 (9.4) years of age, predominantly women $(59 \%, 41)$, with severe airflow limitation (mean $\mathrm{FEV}_{1} 40.2 \%$ ) and highly symptomatic (Medical Research Council breathlessness scale (MRC) 3.4 and CAT 16.8), which is representative for a population of patients hospitalised with acute exacerbation of COPD in Denmark. ${ }^{17}$ Exercise capacities at baseline were 180 (IQR 100.0-240.0) $\mathrm{m}$ on 


\begin{tabular}{|c|c|c|}
\hline Characteristics & & All patients \\
\hline $\mathrm{N}$ & & 70 \\
\hline Age (years), mean (SD) & & $72.7(9.4)$ \\
\hline \multirow[t]{2}{*}{ Sex, n (\%) } & Male & $29(41 \%)$ \\
\hline & Female & $41(59 \%)$ \\
\hline $\mathrm{FEV}_{1}$ (litres), mean (SD) & & $1.0(0.4)$ \\
\hline $\mathrm{FEV}_{1}(\%$ predicted), mean (SD) & & $40(15)$ \\
\hline MRC, mean (SD) & & $3.4(0.9)$ \\
\hline CAT, mean (SD) & & $16.8(6.0)$ \\
\hline $\begin{array}{l}\text { Saturation without } \mathrm{O}_{2} \text { supplement (\%), } \\
\text { mean (SD) }\end{array}$ & & $1.0(0.0)$ \\
\hline \multirow[t]{2}{*}{ Long-term oxygen therapy, n (\%) } & No & $63(95 \%)$ \\
\hline & Yes & $3(5 \%)$ \\
\hline BMI $\left(\mathrm{kg} / \mathrm{m}^{2}\right)$, mean $(\mathrm{SD})$ & & $23.5(4.6)$ \\
\hline \multirow[t]{3}{*}{ Smoking status, n (\%) } & Current & $22(31 \%)$ \\
\hline & Former & $45(64 \%)$ \\
\hline & Never & $3(4 \%)$ \\
\hline Pack-years, mean (SD) & & $40.6(16.5)$ \\
\hline \multirow[t]{2}{*}{ Leaving the house daily } & No & $25(38 \%)$ \\
\hline & Yes & $41(62 \%)$ \\
\hline ISWT (m), median (IQR) & & $\begin{array}{l}180.0(100.0- \\
240.0)\end{array}$ \\
\hline ESWT (s), median (IQR) & & $\begin{array}{l}159.0(119.0- \\
233.5)\end{array}$ \\
\hline ESWT level (pace), median (IQR) & & $6.0(4.0-8.0)$ \\
\hline
\end{tabular}

BMI, body mass index; CAT, COPD Assessment Test; ESWT, endurance shuttle walk test; ISWT, incremental shuttle walk test; MRC, Medical Research Council dyspnoea scale.

the ISWT and 159.0 (IQR 119.0-233.5) s on the ESWT. Table 1 presents the demographic data and baseline measures at the time of inclusion for all patients.

The median number of rehabilitation sessions the patients attended was 8.9. Twelve patients did not attend any rehabilitation sessions, 19 partially attended and 39 met the a priori definition of adherence. Of the patients attending no rehabilitation sessions, three died before the programme commencement, two never began the programme for unknown reasons, and seven did not want to participate in the programme despite agreeing to the study and completing the informed consent.

\section{Hospital readmissions}

The median number of hospital admissions overall was 1 (IQR 0-3) during the 12-month study period.

Modelling of the risk of hospitalisation showed that the crude incidence rate ratio (IRR) of admission was associated with the number of rehabilitation sessions the patient attended (IRR 0.93 (95\% CI 0.88 to 0.99 ), $\mathrm{p}=0.018$ ), corresponding to a reduction of $7 \%$ for each session. After elimination of covariates, age, $\mathrm{FEV}_{1}$, CAT and MRC were retained in the adjusted model. The inclusion of these variables in the model did not alter the estimate (IRR 0.93 (95\% CI 0.88 to 0.99 ), $\mathrm{p}=0.020$ ). Figure 1 illustrates the estimated risk of hospital admission according to the number of rehabilitation sessions the patients attended. The sensitivity analysis showed that adherence (attending at least $75 \%$ of the sessions) was highly associated with a reduction in hospital admissions (OR 0.14 (95\% CI 0.03 to 0.56 ), $\mathrm{p}=0.006$ adjusted for CAT and pack-years).

\section{Secondary outcomes}

The mean ISWT increased by $69 \mathrm{~m}$ (95\% CI 43 to 95) at the completion of the rehabilitation programme, 2 months after inclusion, which is higher than the minimal clinically important difference (MCID) for the ISWT of $47.7 \mathrm{~m} .^{18}$ The univariate model showed a significant association between improvement in ISWT and the number of completed rehabilitation sessions, corresponding to an increase of $8 \mathrm{~m}$ for every rehabilitation session the patients attended (slope $8.05 \mathrm{~m}$ (95\% CI 2.54 to 13.55), $\mathrm{p}=0.005$ ). We tested for all baseline covariates (table 1 ), but after backwards elimination, no covariates were significant, so the multivariate model could not be performed.

The mean improvement in ESWT was 392 s $(95 \%$ CI 278 to 506) at the 2-month follow-up, which exceeds the MCID of 186 to $199 \mathrm{~s} .{ }^{19}$ In addition, we found an association between the number of completed rehabilitation sessions and the ESWT improvement, with an estimated increase of $44 \mathrm{~s}$ per attended session (slope $43.68 \mathrm{~m}(95 \%$ CI 18.41 to 68.95$), \mathrm{p}=0.001$ ). The multivariate model showed similar results (slope $46.58 \mathrm{~m}$ (95\% CI 26.65 to 66.50), $\mathrm{p}=0.000$ ), adjusted for pack-years and smoking status.

The mean change in CAT score for all patients was -3.6 points (95\% CI -5.4 to -1.7$)$ at the 2-month follow-up. The MCID for CAT score in pulmonary rehabilitation is -2.0 points. ${ }^{20}$ No association was found between change in CAT score and the number of completed rehabilitation

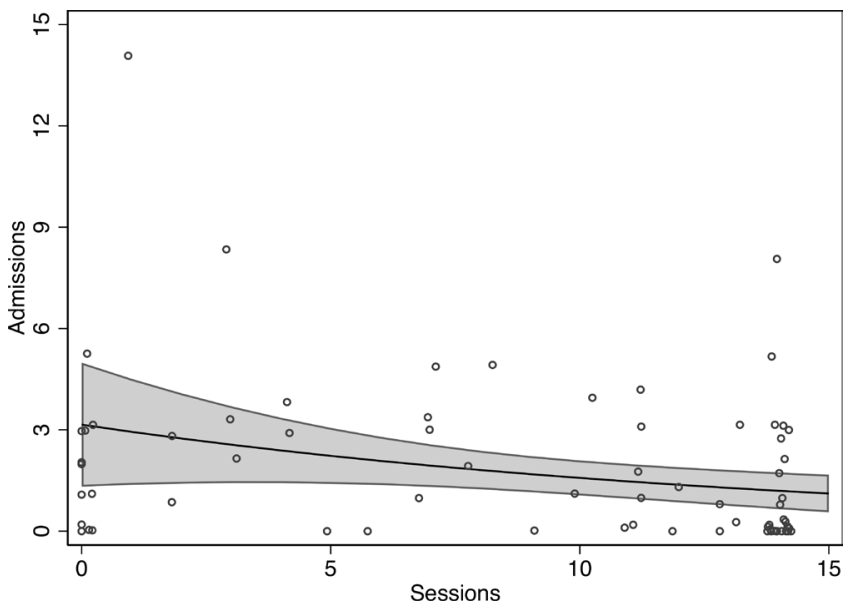

Figure 1 Estimated risk of hospital admission according to number of rehabilitation sessions the patients attended. Incidence rate ratio $0.93(95 \% \mathrm{Cl} 0.88$ to 0.99$), \mathrm{p}=0.02$. 
Table 2 Hospital admissions, physical performance and quality of life (adjusted analysis)

\begin{tabular}{|c|c|c|c|c|c|c|c|}
\hline & & \multicolumn{3}{|c|}{ Unadjusted analysis } & \multirow[b]{2}{*}{ Estimate } & \multicolumn{2}{|c|}{ Adjusted analysis } \\
\hline & & Estimate & $95 \% \mathrm{Cl}$ & $P$ value & & $95 \% \mathrm{Cl}$ & $P$ value \\
\hline Hospital admissions & IRR & 0.93 & 0.88 to 0.99 & 0.018 & 0.93 & 0.88 to 0.99 & 0.020 \\
\hline ISWT (m) & Slope & 8.05 & 2.54 to 13.56 & 0.005 & NA & & \\
\hline ESWT (s) & Slope & 43.68 & 18.41 to 68.95 & 0.001 & 46.58 & 26.65 to 66.50 & 0.000 \\
\hline CAT (points) & Slope & 0.15 & -0.35 to 0.65 & 0.55 & -0.08 & -0.46 to 0.30 & 0.68 \\
\hline
\end{tabular}

Hospital admissions at 12-month follow-up. ISWT, ESWT and CAT at 2-month follow-up. ISWT was not adjusted. ESWT was adjusted for pack-years and smoking status. CAT was adjusted for BMI and CAT at baseline. ISWT, ESWT and CAT were analysed with linear regression. Hospital admissions were analysed with negative binomial regression and adjusted for age, FEV ${ }_{1}, \mathrm{CAT}_{\text {and }} \mathrm{MRC}$ at baseline.

Fit parameters for each model (McFadden's $R^{2}$ ): Hospital admissions: crude model $R^{2}=0.02$ and adj. model $R^{2}=0.08$. ISWT: crude model $R^{2}=0.12$.ESWT: crude model $R^{2}=0.18$ and adj. model $R^{2}=0.41$. CAT:crude model $R^{2}=0.01$ and adj model $R^{2}=0.30$.

CAT, COPD Assessment Test; ESWT, endurance shuttle walk test; ISWT, incremental shuttle walk test; MRC, Medical Research Council dyspnoea scale; NA, not applicable.

sessions in either the univariate model (slope 0.15 points ( $95 \%$ CI -0.35 to 0.65 ), $\mathrm{p}=0.55$ ) or the adjusted model (slope -0.08 points ( $95 \%$ CI -0.46 to 0.30 ), $\mathrm{p}=0.68$ ), adjusted for body mass index and CAT.

Both the crude and adjusted analysis for hospital admissions and secondary outcomes are shown in table 2 .

\section{DISCUSSION}

In the present secondary analysis of the COPD-EXAREHAB study, we focused on the importance of early pulmonary rehabilitation programme attendance following an acute exacerbation of COPD. We found that increased attendance was associated with a reduced risk of hospital admission. Improved physical performance assessed by walking tests was also associated with the number of completed sessions, whereas we did not find any association between attendance and quality of life as assessed by the CAT.

To the best of our knowledge, this is the first paper to investigate the association between the number of rehabilitation sessions attended and outcomes of early pulmonary rehabilitation after an exacerbation of COPD.

A risk reduction corresponding to a reduction in hospital admissions of $7 \%$ per attended rehabilitation session is a considerable effect. We cannot conclude from the data that this is a causal effect, mainly because of the small size and risk of confounding. However, the association remained statistically significant in the adjusted models. The present analyses should be regarded as exploratory and the results should be confirmed in a prospective trial.

Several studies and reviews have shown a reduced risk of hospitalisation after early pulmonary rehabilitation. ${ }^{21}$ However, a review by Moore et al included RCTs, non-randomised cohort studies, and studies comparing before and after rehabilitation. ${ }^{21}$ The original RCT COPD-EXA-REHAB study showed a non-significant reduction in hospital admissions in the early pulmonary rehabilitation group compared with the rehabilitation in stable phase group. ${ }^{15}$ The study participants resembled a general COPD population due to the wide inclusion criteria, which may explain the low adherence to the rehabilitation programme. The results of the present analysis show that increased attendance seems to reduce the risk of hospital admission, suggesting that low adherence is a reason for the overall negative result of the RCT. This is in line with several studies on early pulmonary rehabilitation showing reduced hospital admissions when compared with no rehabilitation, summed up in a 2018 systematic review by Ryrsø et al. ${ }^{22}$

Seven patients in the COPD-EXA-REHAB study did not want to participate in the rehabilitation sessions, although they had read and signed the informed consent and underwent randomisation while admitted for their exacerbation. We did not register the reasons for their change of mind, and we were not allowed to check their medical charts after their drop-out. We know from other studies that one of the main reasons for not attending pulmonary rehabilitation after hospitalisation for a COPD exacerbation is that the patients do not feel well enough. ${ }^{1423}$ A qualitative study of patients who refused pulmonary rehabilitation after exacerbation of COPD also found that some felt shame, self-blame, embarrassment or that they were 'not worthy' of rehabilitation. ${ }^{24}$ Healthcare professionals must consider these aspects when patients decline pulmonary rehabilitation shortly after an exacerbation. In a systematic review of interventions to improve uptake and completion of pulmonary rehabilitation, only one randomised study was identified and showed no effect of the intervention, which used a tablet computer with instructions and a training diary in addition to pulmonary rehabilitation. ${ }^{25} 26$ This clearly illustrates the lack of evidence regarding interventions to improve adherence to pulmonary rehabilitation. Therefore, a Cochrane review including a broad range of study designs is underway, aiming to determine effective interventions to improve uptake and adherence. ${ }^{27}$

We found a significant association between improved physical performance and attendance, which is in line with other studies comparing non-completers and completers of pulmonary rehabilitation. ${ }^{28}{ }^{29}$ Although CAT scores improved significantly, we did not find a significant 
association between the quality of life measured by the CAT and rehabilitation programme attendance.

A potential limitation of this analysis is that we did not have the data on hospital admissions and exacerbations before inclusion in the study. Further, we did not have information on daily physical activity and maintenance training in the follow-up period. Lastly, the original COPD-EXA-REHAB study was a single-centre RCT, which may reduce the generalisability of the results.

\section{CONCLUSION}

We found early pulmonary rehabilitation after discharge from hospital following an exacerbation of COPD was associated with reduced risk of hospital readmission and enhanced physical performance. These results supplement our knowledge of the positive effect of pulmonary rehabilitation shortly after exacerbation of COPD and emphasise the importance of improving rehabilitation programme attendance. However, these findings are exploratory and need to be confirmed in future, prospective studies.

\section{Author affiliations}

${ }^{1}$ Department of Internal Medicine, Respiratory Section, Herlev and Gentofte Hospital, Copenhagen University, Hellerup, Denmark

${ }^{2}$ Department of Physiotherapy and Occupational Therapy, Herlev and Gentofte Hospitals, University of Copenhagen, Hellerup, Denmark

${ }^{3}$ Research Unit for Musculoskeletal Function and Physiotherapy, Department of Sports Science and Clinical Biomechanics, University of Southern Denmark, Odense, Denmark, Odense, Syddanmark, Denmark

${ }^{4}$ Section of Epidemiology, Institute of Public Health, University of Copenhagen Faculty of Health and Medical Sciences, Copenhagen, Denmark

Acknowledgements The authors would like to thank the Department of Respiratory Medicine, Gentofte Hospital, for providing facilities and support, and the rehabilitation staff: Mette Rosenberg, Anette Behring, Pia Kjerrumgaard, Hanne Rohde, Linda Dalhof and Henny Riber.

Contributors JK, CBJ and TW contributed to the design of the study and conception and acquisition of data. JK and CBJ analysed data and TW provided statistical advice. JK, CBJ, PL and TW all contributed to the writing of the manuscript and interpreted and critically revised the work. They have all approved the final version and are accountable for their part of the work.

Funding This study was independent research as part of a PhD studentship funded by the Department of Respiratory Medicine, Gentofte Hospital, Denmark, and the Prevention Fund of the Capital Region in Denmark.

Competing interests None declared.

Patient and public involvement Patients and/or the public were not involved in the design, or conduct, or reporting, or dissemination plans of this research.

Patient consent for publication Not required.

Ethics approval The randomised study from which this sub-analysis derives was approved by the Danish National Committee on Health Research Ethics (H-2-2013143).

Provenance and peer review Not commissioned; externally peer reviewed.

Data availability statement Data are available on reasonable request. The data used for the current study will be made available to other researchers. However, the study group has the obligation to assure that data shared are handled in a way that complies with the science ethics permission and the General Data Protection Regulation. Apart from that, the study group has an ambition that data shared are used for sound scientific purposes by researchers. We encourage researchers who find interest in sharing our data to contact the corresponding author. The corresponding author will then bring this request to the study group. Data will be shared if the aforementioned issues are assessed as compliant.

Open access This is an open access article distributed in accordance with the Creative Commons Attribution Non Commercial (CC BY-NC 4.0) license, which permits others to distribute, remix, adapt, build upon this work non-commercially, and license their derivative works on different terms, provided the original work is properly cited, appropriate credit is given, any changes made indicated, and the use is non-commercial. See: http://creativecommons.org/licenses/by-nc/4.0/.

ORCID iD

Jakob Kjærgaard http://orcid.org/0000-0002-9029-6567

\section{REFERENCES}

1 McCarthy B, Casey D, Devane D, et al. Pulmonary rehabilitation for chronic obstructive pulmonary disease. Cochrane Database Syst Rev 2015:CD003793.

2 Spruit MA, Singh SJ, Garvey C, et al. An official American Thoracic Society/European Respiratory Society statement: key concepts and advances in pulmonary rehabilitation. Am J Respir Crit Care Med 2013;188:e13-64.

3 Puhan MA, Gimeno-Santos E, Cates CJ, et al. Pulmonary rehabilitation following exacerbations of chronic obstructive pulmonary disease. Cochrane Database Syst Rev 2016;12:CD005305

4 Wedzicha JA, Miravitlles M, Hurst JR, et al. Management of COPD exacerbations: a European Respiratory Society/American Thoracic Society guideline. Eur Respir J 2017;49:1600791.

5 NICE. Chronic obstructive pulmonary disease in over 16S: diagnosis and management | guidance and guidelines | NICE, 2010. Available: https://www.nice.org.uk/guidance/ng115/chapter/ Recommendations\#managing-stable-copd [Accessed 2 Apr 2019].

6 Global Initiative for Chronic Obstructive Lung Disease. Global Initiative for Chronic Obstructive Lung Disease (2019 report), 2019. Available: http://www.goldcopd.org [Accessed 2 Apr 2019].

7 Johnston K, Grimmer-Somers K. Pulmonary rehabilitation: overwhelming evidence but lost in translation? Physiother Can 2010;62:368-73.

8 Johnston K, Young M, Grimmer K, et al. Frequency of referral to and attendance at a pulmonary rehabilitation programme amongst patients admitted to a tertiary hospital with chronic obstructive pulmonary disease. Respirology 2013;18:1089-94.

9 Bjoernshave B, Korsgaard J, Nielsen CV. Does pulmonary rehabilitation work in clinical practice? A review on selection and dropout in randomized controlled trials on pulmonary rehabilitation. Clin Epidemiol 2010;2:73-83 http://www.ncbi.nlm.nih.gov/pubmed/ 20865106

10 Cox NS, Oliveira CC, Lahham A, et al. Pulmonary rehabilitation referral and participation are commonly influenced by environment, knowledge, and beliefs about consequences: a systematic review using the Theoretical Domains Framework. J Physiother 2017;63:84-93.

11 Keating A, Lee A, Holland AE. What prevents people with chronic obstructive pulmonary disease from attending pulmonary rehabilitation? A systematic review. Chron Respir Dis 2011;8:89-99.

12 Hayton C, Clark A, Olive S, et al. Barriers to pulmonary rehabilitation: characteristics that predict patient attendance and adherence. Respir Med 2013;107:401-7.

13 Jones SE, Green SA, Clark AL, et al. Pulmonary rehabilitation following hospitalisation for acute exacerbation of COPD: referrals, uptake and adherence. Thorax 2014;69:181-2.

14 Harrison SL, Robertson N, Graham CD, et al. Can we identify patients with different illness schema following an acute exacerbation of COPD: a cluster analysis. Respir Med 2014;108:319-28.

15 Kjærgaard JL, Juhl CB, Lange P, et al. Early pulmonary rehabilitation after acute exacerbation of COPD: a randomised controlled trial. ERJ Open Res 2020;6. doi:10.1183/23120541.00173-2019. [Epub ahead of print: 17 Feb 2020].

16 Danish National Board of Health. National clinical guideline for rehabilitation in patients with COPD (national klinisk retningslinje for rehabilitering AF patienter Med KOL 2018), 2018. Available: https:// www.sst.dk/da/udgivelser/2018/ /media/AD2FF426014943D983E0 D7B937B356B9.ashx [Accessed 11 Jul 2019].

17 Eriksen N, Vestbo J. Management and survival of patients admitted with an exacerbation of COPD: comparison of two Danish patient cohorts. Clin Respir J 2010;4:208-14.

18 Singh SJ, Jones PW, Evans R, et al. Minimum clinically important improvement for the incremental shuttle walking test. Thorax 2008;63:775-7.

19 Altenburg WA, Duiverman ML, Ten Hacken NHT, et al. Changes in the endurance shuttle walk test in COPD patients with chronic respiratory failure after pulmonary rehabilitation: the minimal 
important difference obtained with anchor- and distribution-based method. Respir Res 2015;16:27.

20 Kon SSC, Canavan JL, Jones SE, et al. Minimum clinically important difference for the COPD Assessment Test: a prospective analysis. Lancet Respir Med 2014;2:195-203.

21 Moore E, Palmer T, Newson R, et al. Pulmonary rehabilitation as a mechanism to reduce hospitalizations for acute exacerbations of COPD: a systematic review and meta-analysis. Chest 2016;150:837-59.

22 Ryrsø CK, Godtfredsen NS, Kofod LM, et al. Lower mortality after early supervised pulmonary rehabilitation following COPDexacerbations: a systematic review and meta-analysis. BMC Pulm Med 2018;18:154.

23 Benzo R, Wetzstein M, Neuenfeldt P, et al. Implementation of physical activity programs after COPD hospitalizations: lessons from a randomized study. Chron Respir Dis 2015;12:5-10.

24 Harrison SL, Robertson N, Apps L, et al. "We are not worthy" understanding why patients decline pulmonary rehabilitation following an acute exacerbation of COPD. Disabil Rehabil 2015;37:750-6.
25 Jones AW, Taylor A, Gowler H, et al. Systematic review of interventions to improve patient uptake and completion of pulmonary rehabilitation in COPD. ERJ Open Res 2017;3:000892016-2016.

26 Ringbæk TJ, Brøndum E, Bolton S, et al. Rehabilitering af patienter med kronisk obstruktiv lungesygdom : tolvmånederseffekten af et syvugersprogram. Ugeskr læger 2007;169:1572-6.

27 Young J, Jordan RE, Adab P, et al. Interventions to promote referral, uptake and adherence to pulmonary rehabilitation for people with chronic obstructive pulmonary disease (COPD). Cochrane Database Syst Rev 2017;65.

28 Houchen-Wolloff L, Williams JE, Green RH, et al. Survival following pulmonary rehabilitation in patients with COPD: the effect of program completion and change in incremental shuttle walking test distance. Int J Chron Obstruct Pulmon Dis 2018;13:37-44.

29 Bjoernshave B, Korsgaard J, Jensen C, et al. Participation in pulmonary rehabilitation in routine clinical practice. Clin Respir $J$ 2011:5:235-44. 